\title{
SERUM IGF-1 LEVELS MEASURED BY DIFFERENT ELISA ASSAYS AND IRMA - A COMPARABILITY STUDY
}

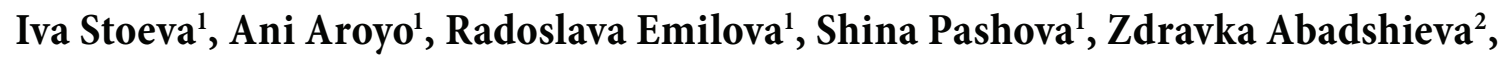 \\ Georgi Kirilov² \\ ${ }^{1}$ University Pediatric Hospital, Medical University Sofia, Bulgaria \\ ${ }^{2}$ Clinical Center of Endocrinologye Gerontology, Medical University Sofia, Bulgaria
}

\begin{abstract}
BACKGROUND: While techniques for measuring IGF-1 have evolved over the decades, immunoassays are still the primary tool used in routine laboratories. ELISA, IRMA and Chemiluminescence IGF-1 kits are today on the market and their calibrators, specificity, sensitivity, cross-reactivity and prices differ substantially. Comparability studies are therefore valuable, especially if IGF-1 results obtained by one method should be interpreted retrospectively after transfer of patients from the pediatric to the adult endocrinologists.

AIM: To determine which of the used ELISA assays is closest to the IRMA IGF-1 assay and responds best to the Consensus Statement IGF-1 requirements from 2011.

MATERIAL AND METHODS: 24 patients aged 37.9 \pm 14.4 years, median 35; 12 females $(42.25 \pm 16.6$, median 38.5); 12 males (33.58 \pm 10.9 , median 34.5$)$ years.

The IGF-1 serum levels were measured by three different assays: Immunoradiometric (IRMA), IGFBPblocked Immunoenzymetric (ELISA1) and Immunoenzymetric with acid-ethanol extraction (ELISA2). The results were interpreted according to the kit referent values adjusted for age and gender.

RESULTS: A very high positive correlation between the three assays $(r=0.986$ to 0.990$)(p<0.01)$ was found. A significant difference was established only regarding the mean IGF-1 values measured by IRMA vs. ELISA2 $(p<0.05)$. The lowest IGF-1 mean value were measured by IRMA.

CONCLUSIONS: Closest to the IRMA method were IGF1 levels measured by the indirect "sandwich" ELISA1 (IGFBP blocked) assay. Due to the significant difference between IRMA and the direct ELISA2 method, diagnostic pitfalls and therapeutic misinterpretations are possible. Priority has to be given to IGF-1 assays which best correspond to the Consensus Statement requirements from 2011. In this study this is fulfilled for the ELISA1, IGF blocked immunoassay. Future developments lie in fully automated assay systems, adapted to pediatric endocrine laboratories.
\end{abstract}

Keywords: Serum IGF-1, ELISA-IGFBP-blocked, acid-ethanol extraction, IRMA, comparison

Address for correspondence:

Iva Stoeva

University Pediatric Hospital,

Medical University Sofia

11 Acad. Ivan Evstatiev Geshov Blvd.

1606 Sofia

e-mail: stoeva_i@abv.bg

Received: January 27, 2014

Accepted: March 11, 2015

\section{INTRODUCTION}

Growth hormone (GH) and insulin-like growth factor 1 (IGF-1) measurements are widely used in evaluation of children with short stature from multiple causes $(13,20)$ as well as in management of disorders that lead to nutritional insufficiency or catabolism. They are cornerstones in the diagnosis of disorders of GH secretion and monitoring both GH (16, $22,23)$ and IGF-1 replacement therapy $(1,12)$. IGF-1 is 
Serum IGF-1 levels measured by different ELISA assays and IRMA - a comparability study

also suggested as an important marker in malignant $(17,19)$ and metabolic diseases $(3,15)$.

The GH secretion has a pulsatile pattern, while serum concentrations of IGF-1 and IGFBP-3 are relatively stable during the day and therefore reflect the general long-term status of $\mathrm{GH}$ secretion.

IGF-1 is the most important peripheral mediator of $\mathrm{GH}$ actions (18). It is a 70-amino acid protein, produced locally in many organs and tissues, but predominantly in the liver upon stimulation by GH. Circulating IGF-1 is bound with high affinity to specific binding proteins (BPs), of which IGFBP-3 is the most abundant, and to an acid-labile subunit (ALS), forming a ternary complex, retained within intravascular space and acting as a circulating reservoir of IGF-1 (4). A variety of factors like gender, age, nutritional status, some pathological conditions, influence IGF1. The age-related pattern of IGF-1 secretion consists in a decline immediately after birth, followed by an increase until a pubertal peak. Later in life, values decrease continuously $(8,14)$. While techniques for measuring IGF-1 have evolved over the decades (9), immunoassays are still the primary tool used in routine laboratories (7). The radioimmunoassays (RIA) were replaced later by the immunoradiometric assays (IRMA), enzyme immunoassays (EIA), fluoroimmunoassays (FIA), automated chemiluminescence (6). Still considerable differences exist due to heterogeneity in assay characteristics between the currently available IGF-1 assays. Clinicians are therefore often challenged in accurate interpreting IGF-1 concentrations. Laboratories have to face substantial problems with establishing new reference values if assay characteristics change $(6,14,16)$. Therefore, the practical utility of IGF-1 is undermined.

Two of the clinical endocrine centers in Sofia for adults and for children, perform IGF-1 determinations by different assays: IRMA (Clinical Center for Endocrinology\&Gerontology) and ELISA (University Pediatric Hospital, no license for work with radioactive materials).

The aim of the current study is to test the comparability of the different non-radiometric assays based on ELISA methods and the IRMA for determination of serum IGF-1.

\section{MATERIALS AND METHODS}

\section{Study design}

Twenty four patients, aged from 19 to 69 years, average age 37.9, median 35 years were examined. Out of them 12 were female (average age 42.3, median 38.5) and 12 male (average age 33.6, median 34.5).

IGF-1 in all samples was measured by three different assays (Table 1). Age, gender, pubertal stage, diagnosis and treatment of the patients were not taken into consideration initially. The results were interpreted according to the kit reference values. Subsequently, the interpretations from the three assays were compared to each other, as well as with the diagnosis and the current treatment of the patients.

\section{Healthy probands}

36 healthy individuals, aged from 11 to 31 , average age 22.9, median 22 years were included in the comparison between the two ELISA assays. Out of them 24 were females (average age 23.2, median 22 years) and 12 males (average age 22.3, median 22 years). The controls were stratified in the followingage groups in order to interpret the measured IGF-1 levels: $10-17$ years ( $\mathrm{n}=3 ; 2$ female and 1 male); $18-30$ years $(\mathrm{n}=31 ; 20$ female and 11 male) and $31-40$ years $(\mathrm{n}=2 ; 2$ female).

The serum of the patients and the healthy probands was collected and after one hour period at room temperature centrifugated at $5000 \mathrm{rpm}$. All samples were stored frozen at $-20 \mathrm{C}^{\circ}$ until the analysis, according to the instructions of the producer.

\section{Analysis of serum IGF-1 levels}

The serum levels of IGF-1 in the target group of patients $(n=24)$ were determined by three different assays:

* Immunoradiometric assay (IRMA IGF-1, Immunotech Beckman Coulter), calibrated against the World Health Organization (WHO) standard NIBSC 87/518. This is an indirect "sandwich" method: the patient's samples are incubated in tubes coated with monoclonal antibody against IGF-1 in the presence of second monoclonal antibody labeled with iodine 125 . The intensity of radioactive reaction is proportional to the concentration of IGF-I in the patient sera.

* IGFBP-blocked enzyme immunoassay (IGF1-ELISA, Mediagnost, Germany), calibrat- 
Iva Stoeva, Ani Aroyo, Radoslava Emilova, et al.

ed against the WHO standard NIBSC 02/254. In order to dissociate IGF-1 from IGFBP's, the samples are diluted in acidic buffer $(\mathrm{pH}<3.1)$. After the following neutralization $(\mathrm{pH}=7)$, an excess IGF-2 occupies the IGF-binding sites of the IGFBPs. The IGFBP's are not removed, but their interference in the assay is neutralized.

The method is an indirect "sandwich" ELISA. The IGF-1 in the samples binds to immobilized first antibody on the microtiter plate, and with a second specific streptavidin-peroxidase conjugated antiIGF-1 Antibody.

* Immunoenzymatic assay with acid-ethanol extraction (IGF-1-ELISA, Diasource Immuno-
Assays S.A., Belgium), calibrated against the WHO standard NIBSC 02/254. The patient's samples undergo a pre-treatment step - the acid-ethanol procedure, proposed by William Daughaday in 1980. Due to the change in $\mathrm{pH}$, IGF-1 and IGFBP's are dissociated. The ethanol dilution precipitates IGFBP's and therefore neutralizes their interference with the assay.

The method is a direct concurrent ELISA. A fixed amount of IGF-1-labeled with horseradish peroxidase (HRP), compete with unlabeled IGF-1 present in the samples for a limited number of binding sites on a specific antibody. After the incubation time, a chromogenic solution is added. The amount

Table 1. Characteristics of the assays, used for determining IGF-1 serum levels

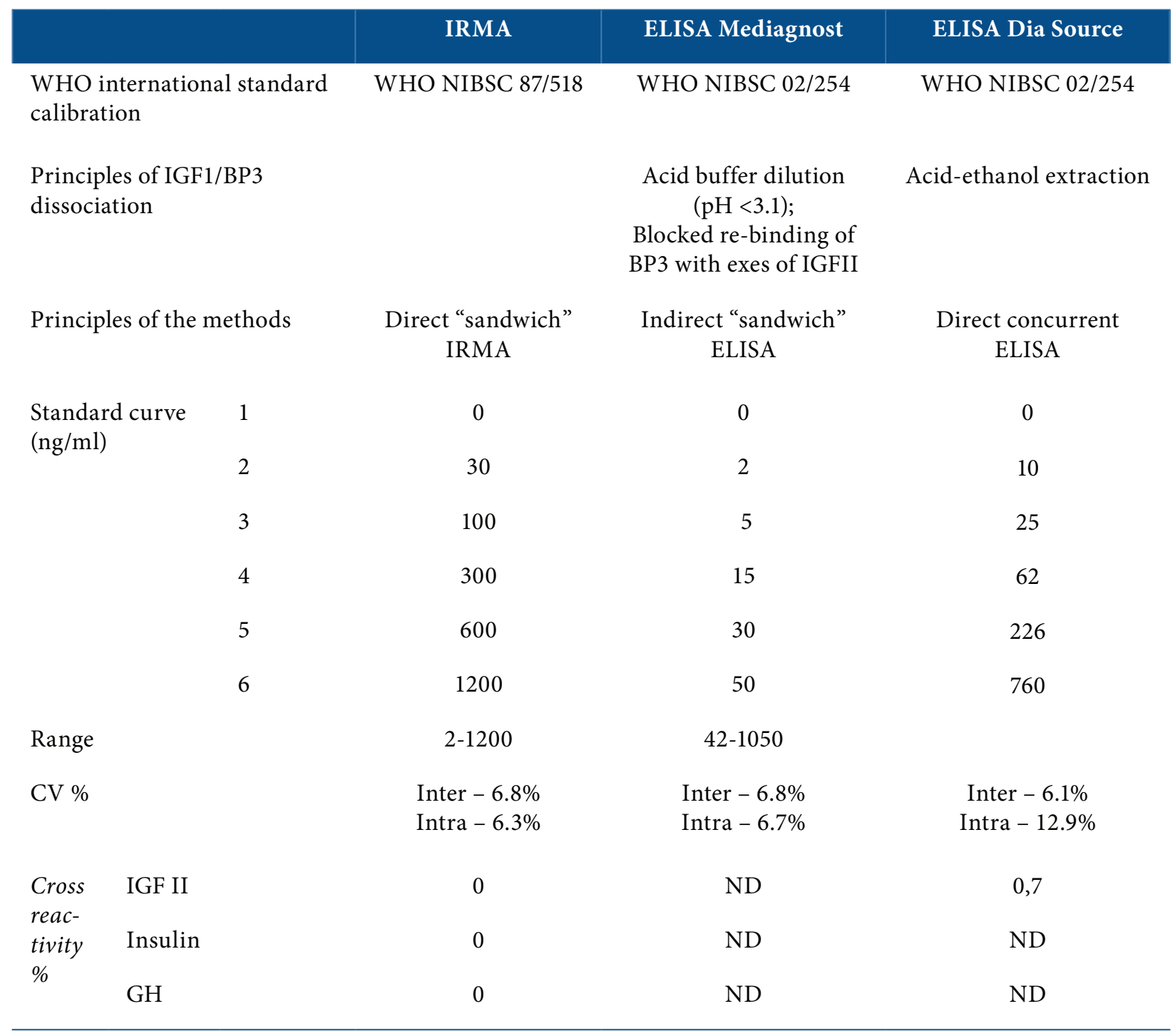


of substrate turnover is determined calorimetrically by measuring the absorbance, which is inversely proportional to the IGF-1 concentration.The most important assay characteristics are summarized in table 1 .

\section{Statistical analysis}

For comparison between the groups we used Student's-Fisher $\mathrm{t}$ - test. The strength of the relationship between the three assays was evaluated by correlation and graphic analysis. To test the agreement between the assays the Bland-Altman method was performed.

\section{RESULTS}

\section{Test of significance}

To assess the difference between the mean IGF1 values of the three assays, a test of significance was performed. There was a significant difference $(p<0.05)$ between the mean values of IGF-1 measured by IRMA and direct concurrent ELISA (Fig. 1, bar 1 and 3). Between the measurements by IRMA and indirect "sandwich" ELISA no significant difference was found $(\mathrm{p}=0.3)$, as well as between the two ELISA

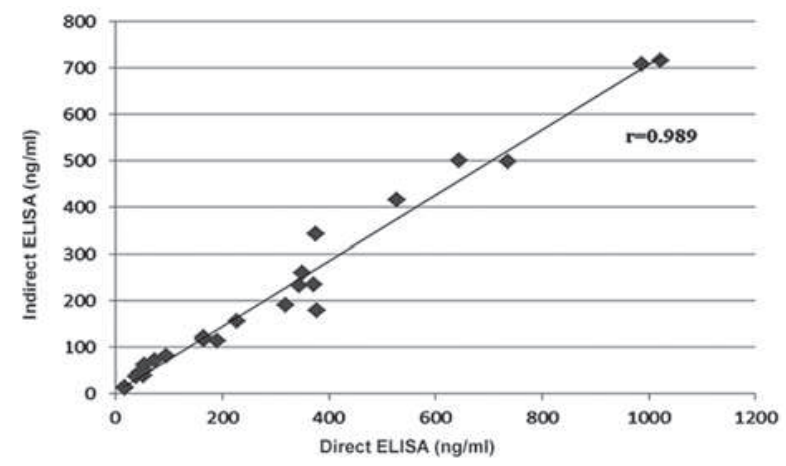

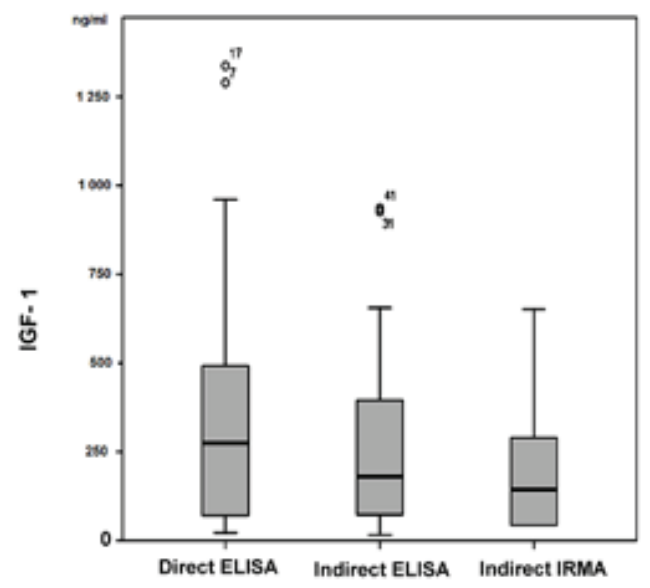

Fig. 1. Comparison of the mean serum IGF-1 values between the three assays: Analysis 1 -direct concurrent ELISA; Analysis 2 - Indirect "sandwich" ELISA; Analysis $3-I R M A$

methods ( $\mathrm{p}=0.25)$ (Fig. 1). The lowest mean levels of IGF-1 were determined by IRMA.

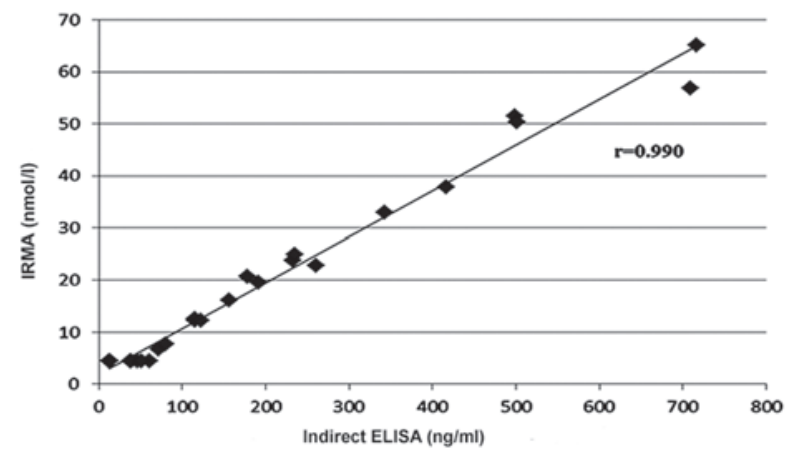

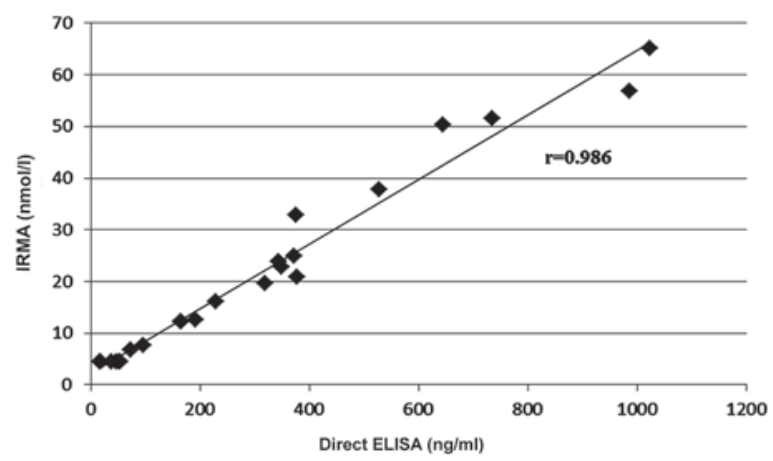

Fig. 2. Correlation between the three assays for determining serum levels of IGF-1; a) A very high positive correlation between indirect "sandwich" ELISA and direct concurrent ELISA; b) A very high positive correlation between indirect "sandwich" ELISA and IRMA; c) A very high positive correlation between direct concurrent ELISA and IRMA 
Iva Stoeva, Ani Aroyo, Radoslava Emilova, et al.

\section{Correlation analysis}

The performed correlation analysis showed a very high positive correlation between the three assays $r=0.986$ to $0.990(p<0.01)($ Fig. 2$)$ and a strong linear relationship between them as well.

\section{Test for agreement between the three assays}

Bland-Altman analysis showed good agreement between indirect "sandwich" ELISA and IRMA (Fig. $3 \mathrm{~b}$ ), with a relatively low bias of $7.3 \mathrm{ng} / \mathrm{ml}$ and acceptable limits of agreement $( \pm 2 S D$ range of the measurement differences). Lesser agreement was found in the comparison of the two ELISA assays (Fig. 3a) with a higher bias of $11.2 \mathrm{ng} / \mathrm{ml}$ and a comparably large limits of agreement. Poor agreement was found between direct concurrent ELISA and IRMA (Fig. 3c) with a bias of $18.5 \mathrm{ng} / \mathrm{ml}$ and large limits of agreement.

\section{DISCUSSION}

Several IGF-1 studies including creation of reference values were undertaken in Bulgaria during the last decade. Methods, as well as patient's groups were different $(2-3,22,23-24)$. This study is aimed to provide some data which could help in choosing the most appropriate assay for diagnosing and controlling treatment of growth hormone deficiency in children and adolescents. The lack of consistency of the different assays, even from one and the same producer, combined with problems in the reagent's supply, represent problems which should be solved in the light of the new Consensus Statement on the Standardization and Evaluation of Growth Hormone and IGF assays (12). The need for harmonization of the IGF-1 assays is challenging also the Bulgarian endocrinologists - the pediatricians as well the internists.

In the present study we could show substantial differences between the mean IGF-1 concentrations in one and the same patients and healthy probands by two different ELISA assays and IRMA. The highest IGF-1 levels were measured by direct ELISA (Immunoenzymatic assay with acid-ethanol extraction), followed by the other ELISA assay (IGFBP blocked) and the IRMA. The IGF-1 difference was significant only between the ELISA with acid-ethanol extraction and the IRMA assay (Fig. 1). These findings are not unexpected, and the differences of results among assays are most probably due to the methodology, different calibrators and study cohorts.
In general, immunoassays 'measure' the interaction between the analyte and specific antibodies that bind to a distinct 3-dimensional structure on the surface of the analyte, or 'epitope'. The binding of the analyte is translated into a measurable signal in various ways, depending on the assay design. In all immunoassays, the signal generated from a given patient's sample is compared with the signal generated by a known amount of the analyte in a series of standardized samples (standard curve). The measurement principle used for quantification of analytes has two major limitations, the antibody specifity and the standard preparation used. Depending on the antibody specifity, any modification of the accessibility of an epitope recognized by the antibody will also modify the assay's result. The presence or absence of IGFBP's in a sample presents a major challenge, as high affinity BP's can 'cover' epitopes recognized by the antibodies used in an assay (7). In general, IGFBP's interfere with IGF-1 detection to produce falsely low values (12). All IGF-1 assays involve some kind of extraction or at least acidification to dissociate the complexes formed by IGF-1, IGFBP's and ALS. The methods differ significantly in their ability to remove IGFBP's completely. The acid-ethanol extraction does not sufficiently eliminate potential interference from smaller IGFBP's $(5,21)$. The disadvantages of the classic extraction procedures can be circumvented by blocking the IGFBP-binding sites through an excess of non-measured IGF-2 in the IGF-1 assay (9-10). Because highly specific antibodies to IGF-1 do not cross-react with IGF-2, an excess of IGF-2 is added during the acid-ethanol precipitation step, before IGF-1 measurement. The high concentration of IGF-2 blocks the IGF-1 binding sites of the remaining BP's, thereby allowing an unbiased measurement of IGF-1. Two steps take place before the IGF-1 measurement: separation of IGF-1 and IGFBP's and then removal of IGFBP's ("functional separation of IGF's from IGFBP's") to prevent re-association. This third generation IGF assays offers a number of advantages over assays using extraction procedures, because they are: a) more simple, b) more precise, c) markedly more sensitive, d) completely suitable for fully automated systems. Therefore, the different IGFBP elimination methods in the three assays could be a very important factor explaining the differences in the 


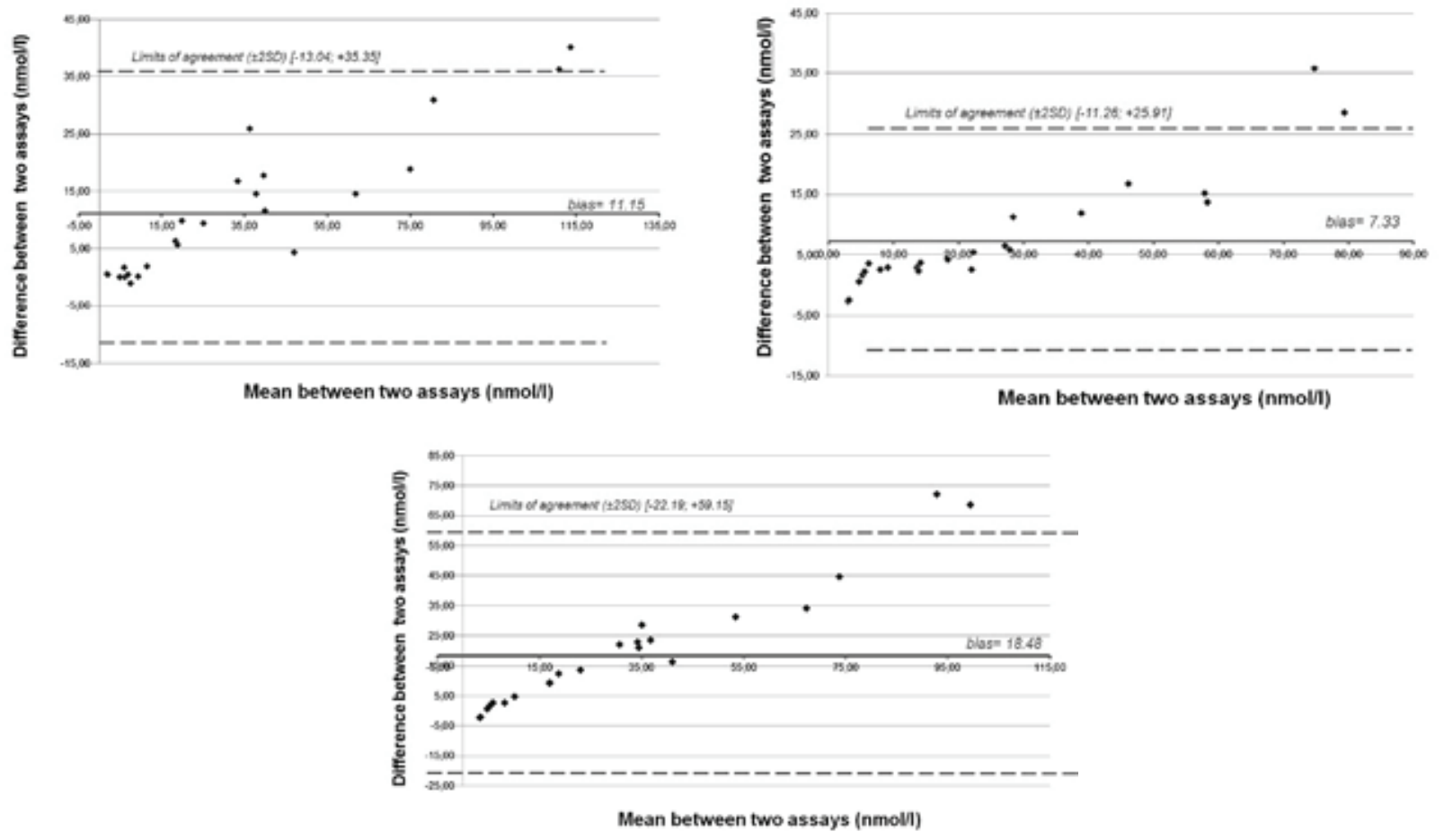

Fig. $3 a, 3 b, 3 c$

mean serum IGF-1 levels in our patients and healthy probands.

Another issue affecting the comparability of IGF-1 assay results is assay standardization. The international reference preparation $87 / 518$ is impure, containing approximately 40\% IGF-1 (25) and is used in the IRMA assay. The IS 02/254 WHO reference standard has recently became available. It is a $>97 \%$ pure recombinant standard and therefore recommended officially (12) in order to minimize the interassay differences that arise from use of different standards. The mean IGF-1 values obtained by the ELISA assays are higher and closer to each other than the results obtained by IRMA, also due to the usage of the recommended 02/254 WHO reference standard.

We included in the study patients with growth hormone deficiency (GHD) before and during treatment with recombinant human (rh) rhGH and healthy subjects as well. The individuals were one and the same in order to exclude variations in IGF1 levels due to differences in the investigated cohort.

Direct comparisons of IGF-1 levels are difficult because of methodological and standards differences. From our data, there is a strong correlation between the three assays $r=0.986$ to $r=0.990$ (Fig. 2a, b, c). Therefore it is safe to conclude that the measurements are related. This result is expected and in agreement with other studies (8). Nevertheless a high correlation does not mean that two methods agree, or prove that they are replaceable.

To understand how much one method (non-radiometric ELISA assays) is likely to differ from the IRMA, an evaluation of the agreement between the assays is required. If the estimated difference is not enough to cause misinterpretation, they can replace one another.

The Bland-Altman plot was used for estimation of the agreement between the assays. This plot was introduced in 1986 by Martin Bland and Douglas Altman. They propose an alternative way of comparing different measurement methods by plotting not the actual values against each other, but the differences against the mean values (11).

To understand how much the estimated agreement would affect the clinical interpretation of the result, a calculation of the mean differences, or bias (d), and the standard deviation of the differences is needed. It is expected for most of the differences (95\%) to lie between $d+2 S D$ and $d-2 S D$, if they are normally distributed. Those limits are referred as a 
Iva Stoeva, Ani Aroyo, Radoslava Emilova, et al.

"limits of agreement". If the limits are within $\mathrm{d} \pm 2 \mathrm{SD}$, they would not be clinically important and the assays could be used interchangeably.

We found that the indirect "sandwich" ELISA1 (IGFBP blocked) and IRMA are in good agreement, with relatively low bias of $7.3 \mathrm{ng} / \mathrm{ml}$ and acceptable limits of agreement (Fig. 3b). This result leads to the conclusion that the probability of misinterpretation is relatively low if IGF-1 comparison between the two centers is needed.

Lesser agreement was found in the comparison of the two ELISA assays (Fig. 3a) with a higher bias of $11.2 \mathrm{ng} / \mathrm{ml}$ and a comparably large limits of agreement. Usage of direct concurrent ELISA2 instead of indirect "sandwich" ELISA1 could result in higher levels of serum IGF-1 followed by false interpretation of the analysis. This may lead to missing the diagnosis GHD or to incorrect dosing of rhGH.

Poor agreement was found between direct concurrent ELISA2 and IRMA (Fig. 3c) with a bias of $18.5 \mathrm{ng} / \mathrm{ml}$ and large limits of agreement. These two methods do not agree with each other. The use of direct concurrent ELISA can cause under- or over-diagnosis and under- or overtreatment.

\section{CONCLUSIONS}

Closest to the IRMA method were IGF-1 levels measured by the indirect "sandwich" ELISA1 (IGFBP blocked) assay. Due to the significant difference between IRMA and the direct ELISA method, diagnostic pitfalls and therapeutic misinterpretations are possible, especially in borderline cases. Priority has to be given to IGF-1 assays which best correspond to the Consensus Statement requirements from 2011. In this study this is fulfilled for the ELISA IGF blocked immunoassay. Future developments lie in fully automated assay systems, adapted especially for pediatric endocrine laboratories.

\section{ACKNOWLEDGEMENTS}

Grant: 57/2011 Medical University Sofia

\section{REFERENCES}

1. Anckaert E, J Schiettecatte, J Vanbesien, J Smitz, B Velkeniers, J De Schepper. Variability among five different commercial IGF-1 immunoassays in conditions of childhood-onset GH deficiency and GH therapy. Acta Clin Belg, 2006;61(6):335-339.
2. Archinkova M, K Koprivarova. Insulin-like growth factors and characteristics of the $\mathrm{GH}$ IGF1 axis in childhood. Pediatria, 2003;28-12 (in Bulgarian).

3. Archinkova M, K Koprivarova, G Kirilov, Z Abadshieva. Serum levels of growth hormone and Insulin-like growth factor-1 in children with Type 1 diabetes. Endocrinologia, 2003;8(2):79-85 (in Bulgarian).

4. Baxter RC. Characterization of the acid-labile subunit of the growth hormone- dependent insulin-like growth factor binding protein complex. J Clin Endocrinol Metab, 1988;67:265-272.

5. Baxter RC. Inhibition of the insulin-like growth factor (IGF)-IGF-binding protein interaction. Horm Res, 2001;55(suppl.2):68-72.

6. Bedogni G, G Giannone, M Maghnie, C Giacomozzi, N Di Iorgi, S Pedicelli et al. Serum insulin-like growth factor-I (IGF-I) reference ranges for chemiluminescence assay in childhood and adolescence. Data from a population of inand out-patients. Growth Hormone IGF Res, 2012;22(3-4):134-138.

7. Bidlingmaier M. Pitfalls in insulin-like growth factor I assays. Horm Res Paedatr, 2009;71(suppl 1):30-33.

8. Bidlingmaier M, N Friedrich, RT Emeny, J Spranger, OD Wolthers, J Roswall et al. Reference Intervals for Insulin-like Growth Factor-1 (IGF-I) From Birth to Senescence: Results From a Multicenter Study Using a New Automated Chemiluminescence IGF-I Immunoassay Conforming to Recent International Recommendations. J Clin Endocrinol Metab. 2014 May;99(5):1712-21.

9. Blum WF, MB Ranke, JR Bierich. A specific radioimmunoassay for insulin-like growth factor II: the interference of IGF binding proteins can be blocked by excess of IGF-I. Acta Endocrinol (Copenh) 1988;118:374-380.

10. Blum WF, BH Breier. Radioimmunoassays for IGFs and IGFBPs. Growth Regul, 1994;4(Suppl.1):11-19.

11. Bland M, D Altman. Statistical methods for assessing agreement between two methods of clinical measurement. Lancet, 1986;1(8476):307-310.

12. Clemmons DR. Consensus Statement on the Standartization and Evaluation of Growth Hormone and Insulin-like Growth Factor Assays. Clinical Chemistry, 2011;57(4):555-559. 
13. David A, V Hwa, L Metherell, I Netchine, $C$ Camacho-Huebner, AJ Clark, RG Rosenfeld, MD Savage. Evidence for a Continuum of Genetic, Phenotypic, and Biochemical Abnormalities in Children with Growth Hormone Insensitivity. Endocrine Rev, 2011;32(4):472-497.

14. Friedrich N, D Alte, H Volzke, E Spilcke-Lies, J Luedemann, MM Lerch, T Kohlmann et al. Reference ranges of serum IGF-1 and IGFBP-3 levels in a general adult population: Results of the study of health in Pomerania (SHIP). Growth Hormone IGF Res., 2008;18(3):228-237.

15. Friedrich N, B Thuesen, T Jorgensen, A Juul, C Spielhagen, H Wallaschofski, A Linneberg. The association between IGF-1 and insulin resistance: a general population study in Danish adults. Diabetes care, 2012;35:768-773.

16. Hauffa B, N Lehmann, M Bettendorf, O Mehls, HG Doerr, N Stahnke, H. Steinkamp et al. Central laboratory reassessment of IGF-I, IGFbinding protein-3, and GH serum concentrations measured at local treatment centres in growthimpaired children: implication for agreement between outpatient screening and the results of somatotropic axis functional testing. Eur J Endocrinol, 2007;157(5):597-603.

17. Key TG, PN Appleby, GK Reeves, AW Roddam. Insulin-like growth factor 1 (IGF1), IGF binding protein 3 (IGFBP3), and breast cancer risk: pooled individual data analysis of 17 prospective studies. Lancet Oncol, 2010;11:530-542.

18. LeRoith D, C Bondy, S Yakar, JL Liu, A Butler. The somatomedin hypothesis: 2001. Endocr Rev, 2001;22(1):53-74.

19. Nimptsch K, AE Platz, M Pollak, SA Kenfield, MJ Stampfer, WC Willet, E Giovannucci. Plasma insulin-like growth factor 1 is positively associated with low-grade prostate cancer in the Health Professionals Follow-up Study 1993-2004. Int J Cancer, 2011;128(3):660-667.

20. Peneva L. The accumulation of bone mass in adolescents determine the risk of osteoporosis. Influence of growth hormone and IGF1. Pediatria, 2012, 2, 6-9 (In Bulgarian).

21. Ranke M, U Feldt-Rasmussen, P Bang, RC Baxter, C Camacho-Huebner, D Clemmons, A Juul, H Orskov, Ch Strasburger. How Should InsulinLike Growth Factor 1 Be Measured? Horm Res, 2001;55(Suppl.2):106-109.
22. Stoeva I, L Sheleva, G Dineva. First results of IGF-1 and IGFBP-3 in children with hyposomatotropism. Pediatria, 2003;3:21-25 (in Bulgarian).

23. Uzunova I, G Kirilov, S Zacharieva, A Shinkov, AM Borissova. Prevalence and Characteristics of the Metabolic Syndrome in Adult Patients with Growth Hormone Deficiency - a comparative study. Endocrinologia, 2013;4:178-188 (in Bulgarian).

24. Uzunova I, G Kirilov, S Zacharieva, A Shinkov, AM Borissova, K Kalinov. Individual Risk Factors of the Metabolic Syndrome in Adult Patients with Growth Hormone Deficiency - A Crosssectional Case-control Study. Exp Clin Endocrinol Diabetes 2014; 122: 1-5 (DOI http://dx.doi. org/10.1055/s-0034-1390460) in print.

25. Quarmby V, C Quan. How much insulin-like growth factor (IGF-1) circulates? Impact of standardization on IGF-1 assay accuracy. Dev Biol Stand, 1999;97:111-118. 